\title{
A simple postoperative oral physiotherapy aid for edentulous patients with oral submucous fibrosis
}

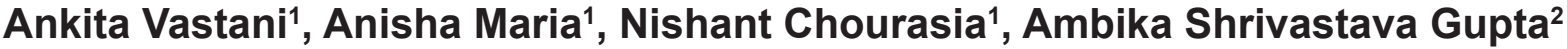 \\ ${ }^{1}$ Department of Oral and Maxillofacial Surgery, Rishiraj College of Dental Sciences and Research Centre, Bhopal 462036, Madhya Pradesh, \\ India. \\ ${ }^{2}$ Department of Prosthodontics, Rishiraj College of Dental Sciences and Research Centre, Bhopal 462036, Madhya Pradesh, India.
}

Address for correspondence: Dr. Ankita Vastani, Department of Oral and Maxillofacial Surgery, Rishiraj College of Dental Sciences and Research Centre, Bhopal 462036, Madhya Pradesh, India. E-mail: ankitavastani@gmail.com.

Sir,

Oral submucous fibrosis is a chronic inflammatory disease, which results in progressive juxta-epithelial fibrosis of the oral soft tissues and can cause increasing difficulty in chewing, swallowing, speaking and mouth opening. ${ }^{[1]}$ Management of the disease, being medical or surgical, poses a great challenge because of the tendency to recur or undergo malignant transformation.

For the management of oral submucous fibrosis, our institution follows a protocol. This includes bilateral surgical release of fibrous bands, bilateral coronoidectomy, extraction of all third molars and reconstruction of intraoral defects using the buccal pad of fat and vigorous postoperative oral physiotherapy with mouth gags.

Application of interocclusal forces to achieve adequate mouth opening forms an integral part of the treatment of oral submucous fibrosis. ${ }^{[2]}$ The oral physiotherapy aids that are currently in use, range from wooden spatulas to mouth gags (such as Heister or Ferguson). Patients with good dentition are amenable to the application of such forces but in edentulous patients, the forces get directly transmitted to the atrophic ridges rendering them vulnerable to fracture and soft tissue injury. ${ }^{[2]}$

Custom made occlusal splints with grooves (for seating of a mouth gag) have already been described as an adjunct to oral submucous fibrosis surgery. ${ }^{[1-3]}$ In this letter, we describe oral stents with occlusal rims without grooves,

\begin{tabular}{|l|l|}
\multicolumn{2}{|c|}{ Access this article online } \\
\hline Quick Response Code: & Website: \\
\hline & www.parjournal.net \\
\cline { 2 - 2 } & \\
\hline
\end{tabular}

aimed for oral physiotherapy in patients without the use of a mouth gag.

This technique involves taking impressions of the maxillary and mandibular edentulous areas using perforated trays. Customized special trays are then fabricated and border molding is performed. Next, these trays are used to make impressions to create heat cure denture bases with occlusal rims on the mandibular denture base [Figure 1]. These denture bases are seated in the patient's mouth [Figure 2] and vertical height of the occlusal rim can be adjusted chair side. If more vertical height is required, then acrylic can be added on the maxillary base plate. The purpose of adding the occlusal rims on denture bases is to maintain mouth opening without having to rely on patient's compliance to actively open the mouth. The patients are supposed to wear these dentures when they want to perform physiotherapy. These dentures are economical, easy to maneuver by the



Figure 1: Heat cure acrylic resin denture bases with occlusal rims

This is an open access article distributed under the terms of the Creative Commons Attribution-NonCommercial-ShareAlike 3.0 License, which allows others to remix, tweak, and build upon the work non-commercially, as long as the author is credited and the new creations are licensed under the identical terms.

How to cite this article: Vastani A, Maria A, Chourasia N, Gupta AS. A simple postoperative oral physiotherapy aid for edentulous patients with oral submucous fibrosis. Plast Aesthet Res 2015;2:299-300.

Received: 23-04-2015; Accepted: 18-05-2015 




Figure 2: Dentures seated in the patient's mouth, forcing the mouth to be opened in this position

patient himself/herself, comfortable and maintenance free. After the tissues heal, procedures for permanent dentures (with teeth) can be performed.
To conclude, this letter described a simple postoperative oral physiotherapy aid for edentulous patients undergoing oral submucous fibrosis surgery. It is the authors hope that it could be beneficial to the surgical community and patients suffering from this condition.

\section{Financial support and sponsorship}

Nil.

\section{Conflicts of interest}

There are no conflicts of interest.

\section{REFERENCES}

I. Le PV, Gornitsky M, Domanowski G. Oral stent as treatment adjunct for oral submucous fibrosis. Oral Surg Oral Med Oral Pathol Oral Radiol Endod 1996:81:48-50.

2. Mahajan AD, Tatu RJ, Shenoy NA, Sharma VS. Surgical management of oral submucous fibrosis in an edentulous patient: a procedural challenge. Natl J Maxillofac Surg 2010;1:161-3.

3. Rai A, Bhola N, Agrawal B, Rai N. A modified technique for postoperative physiotherapy in edentulous patients. J Maxillofac Oral Surg 2012; I 1:247-8. 